\title{
Characterization of the canine CLCN3 gene and evaluation as candidate for late-onset NCL Anne Wohlke ${ }^{1}$, Ottmar Distl ${ }^{1}$ and Cord Drogemuller*2
}

Address: ${ }^{1}$ Institute for Animal Breeding and Genetics, University of Veterinary Medicine Hannover, Bünteweg 17p, 30559 Hannover, Germany and 2 Institute of Genetics, Vetsuisse, University of Berne, Bremgartenstrasse 109a, 3001 Berne, Switzerland

Email: Anne Wohlke - anne.woehlke@tiho-hannover.de; Ottmar Distl - ottmar.distl@tiho-hannover.de; Cord Drogemuller* - cord.droegemueller@itz.unibe.ch

* Corresponding author

Published: 03 March 2006

BMC Genetics2006, 7:13 doi:10.1186/147|-2156-7-13
Received: 10 December 2005

Accepted: 03 March 2006

This article is available from: http://www.biomedcentral.com/I47/-2/56/7//3

(c) 2006Wohlke et al; licensee BioMed Central Ltd.

This is an Open Access article distributed under the terms of the Creative Commons Attribution License (http://creativecommons.org/licenses/by/2.0), which permits unrestricted use, distribution, and reproduction in any medium, provided the original work is properly cited.

\begin{abstract}
Background: The neuronal ceroid lipofuscinoses $(\mathrm{NCL})$ are a heterogenous group of inherited progressive neurodegenerative diseases in different mammalian species. Tibetan Terrier and Polish Owczarek Nizinny (PON) dogs show rare late-onset $\mathrm{NCL}$ variants with autosomal recessive inheritance, which can not be explained by mutations of known human NCL genes. These dog breeds represent animal models for human late-onset NCL. In mice the chloride channel 3 gene (Clcn3) encoding an intracellular chloride channel was described to cause a phenotype similar to $\mathrm{NCL}$.
\end{abstract}

Results: Two full-length cDNA splice variants of the canine CLCN3 gene are reported. The current canine whole genome sequence assembly was used for gene structure analyses and revealed 13 coding CLCN3 exons in $52 \mathrm{~kb}$ of genomic sequence. Sequence analysis of the coding exons and flanking intron regions of CLCN3 using six NCL-affected Tibetan terrier dogs and an NCL-affected Polish Owczarek Nizinny (PON) dog, as well as eight healthy Tibetan terrier dogs revealed 13 SNPs. No consistent CLCN3 haplotype was associated with NCL.

Conclusion: For the examined animals we excluded the complete coding region and adjacent intronic regions of canine CLCN3 to harbor disease-causing mutations. Therefore it seems to be unlikely that a mutation in this gene is responsible for the late-onset $\mathrm{NCL}$ phenotype in these two dog breeds.

\section{Background}

Neuronal ceroid lipofuscinoses (NCL) represents a group of heritable neurodegenerative storage diseases in man, mice, and several domestic animals like cattle, sheep, goat, cat, and certain dog breeds [1]. NCL diseases are characterized by the accumulation of autofluorescent cytoplasmic storage bodies in cells of the brain and retina. NCL diseases cause neurological symptoms that progress relentlessly and culminate in a vegetative state in humans and premature death [2]. Canine late-onset NCL variants primarily affect Tibetan Terrier and Polish Owczarek Nizinny (PON) dogs. A monogenic autosomal recessive mode of transmission was suggested for those breeds $[3,4]$. NCL-affected dogs represent valuable animal models to study human late-onset NCL variants since human families segregating for adult NCL are infrequent. Human NCL is a genetically heterogeneous disease with six identified disease genes (PPT1, TPP1, CLN3, CLN5, CLN6 and 



Figure I

Genomic structure of the canine CLCN3 gene. Translated exons are shown as solid boxes, untranslated regions of exons as shaded boxes. The two alternative gene transcripts are shown below.

CLN8) [5]. Causal mutations within the canine orthologs of the six known human NCL genes have not been identified in NCL-affected Tibetan Terrier and PON dogs [6-9]. Single point mutations in the coding regions of the canine CLN8 and CLN5 genes were found in affected English Setter and Border collie dogs, respectively, showing juvenile NCL $[6,10]$. There are still undiscovered loci causing NCL beside the six known human genes, as indicated by findings in NCL-affected domestic and laboratory animals. In White Swedish Landrace sheep a CTSD mutation was reported and a mutation within the ortholog canine CTSD gene was detected in NCL-affected American Bulldogs [11]. Recently, CTSD was excluded as candidate gene in NCL-affected Tibetan Terrier and PON dogs [12]. In mice the chloride channel 3 gene (Clcn3) encoding an intracellular chloride channel was described to cause a phenotype similar to NCL [13]. Clcn3-deficient mice are characterized by developmental retardation and higher mortality combined with neurological manifestations such as blindness, motor coordination deficit, and spontaneous hyperlocomotion similar to human and canine NCL. To evaluate whether the CLCN3 gene is involved in the NCLaffected Tibetan Terrier and PON dogs, we determined the full-length cDNA sequence, characterized the gene struc- ture, and analyzed the coding sequence of the canine ortholog.

\section{Results and discussion Sequence analysis}

RT-PCR from canine lung mRNA amplified two splice variants, which were verified by direct DNA-sequencing of the RT-PCR products. Similar to the human CLCN3 sequence the alternative usage of exon 12 produces the shorter CLCN3 and the longer CLCN3 isoform e, respectively (Figure 1). Overlapping canine cDNA fragments containing all junctions between the exons were generated by RT-PCR, sequenced, and used for comparison with the genomic sequence. These analyses indicated that the canine CLCN3 gene consists of 13 exons separated by twelve introns. The canine CLCN3 gene spans $52 \mathrm{~kb}$ (Figure 1) compared to 14 exons over $100 \mathrm{~kb}$ in human CLCN3 (NCBI build 35.1)) because in dog no untranslated 5'-exon is used. All splice donor/splice acceptor sites conform to the GT/AG rule. The experimentally verified existence of the two alternative splice variants is in agreement with the initially identified canine 5'-EST sequences (Figure 1). In dog the shorter CLCN3 transcript [EMBL:AM048629] contains an open reading frame of 
Table I: Polymorphisms and observed haplotypes in the canine CLCN3 gene

\begin{tabular}{|c|c|c|c|c|c|c|c|c|c|c|}
\hline \multirow[t]{2}{*}{ Position 1} & \multirow[t]{2}{*}{ Boxer $^{2}$} & \multirow[t]{2}{*}{ Haplotype } & \multicolumn{6}{|c|}{ Tibetan Terrier } & \multicolumn{2}{|c|}{ PON } \\
\hline & & & I & 2 & 3 & 4 & 5 & 6 & 1 & 2 \\
\hline intron I & 16409 & $\mathrm{~T}$ & $\mathrm{~T}$ & $\mathrm{~T}$ & $\mathrm{~T}$ & $\mathrm{~T}$ & $\mathrm{~T}$ & $\mathrm{~T}$ & $\mathrm{~T}$ & C \\
\hline exon 2 & 2 & A & $A$ & A & $A$ & $A$ & $A$ & G & $A$ & A \\
\hline intron 2 & 3 & G & A & G & G & A & G & A & G & G \\
\hline intron 5 & 10 & G & A & A & A & A & A & A & $A$ & A \\
\hline intron 6 & 40 & $A$ & $A$ & A & A & $A$ & A & A & del & del \\
\hline intron 6 & 2861 & $\mathrm{~T}$ & $\mathrm{~T}$ & $\mathrm{~T}$ & C & C & $\mathrm{T}$ & $\mathrm{T}$ & $\mathrm{T}$ & $\mathrm{T}$ \\
\hline intron 6 & 3061 & C & G & G & G & G & G & C & G & G \\
\hline intron 6 & 3266 & G & $A$ & $A$ & $A$ & $A$ & $A$ & G & $A$ & A \\
\hline intron 6 & 3270 & G & $A$ & G & G & $A$ & $A$ & A & G & G \\
\hline intron 6 & 3291 & $\mathrm{C}$ & $\mathrm{T}$ & $\mathrm{T}$ & $\mathrm{T}$ & $\mathrm{T}$ & $\mathrm{T}$ & $\mathrm{C}$ & $\mathrm{T}$ & $\mathrm{T}$ \\
\hline intron 7 & 38 & G & G & A & G & G & G & G & G & G \\
\hline intron 7 & 144 & C & $T$ & C & $\mathrm{T}$ & $\mathrm{T}$ & $\mathrm{T}$ & $\mathrm{T}$ & C & C \\
\hline exon 9 & 6 & A & G & G & G & G & G & G & G & G \\
\hline
\end{tabular}

I Numbering refers to the position of the polymorphic nucleotide within the given exon or intron respectively.

2 Nucleotide refers to the publicly available dog genome sequence (AAEX01020012) from the boxer named Tasha.

2,376 bp encoding a protein of 791 amino acids. The longer canine CLCN3 isoform e transcript [EMBL:AM048628] contains an open reading frame of 2,517 bp encoding a sequence of 838 amino acids.

\section{Mutation analysis}

A total of 13 sequence polymorphisms (Table 1) were found in the examined dogs as compared to the CLCN3 reference sequence of the current dog genome assembly (boxer genome assembly 1.1). The codon in exon 2 with the $\mathrm{A} / \mathrm{G}$ transition codes for glycine in both SNP variants and the codon in exon 9 with the $\mathrm{A} / \mathrm{G}$ transition codes for proline in both SNP variants. None of the 11 intronic polymorphisms did affect splice sites in the CLCN3 gene. For the single PON dog there were seven polymorphisms compared to the Boxer reference sequence (Table 1).

Assuming linkage disequilibrium between the polymorphic loci six different haplotypes could be constructed for the SNP genotypes in the Tibetan Terrier dogs (Table 1). Four out of six haplotypes occurred in both, affected and unaffected dogs, respectively (Table 2 ). Only the haplotypes 3 and 4 occurred in a single heterozygous NCLaffected Tibetan Terrier dog (Table 2). Due to the assumption of a single recessive founder mutation within this breed we expect homozygosity in affected individuals. Table 2 summarizes the haplotype distribution among the
NCL-affected and the clinical unsuspicious dogs. The chisquare statistic for testing these haplotypes for association with disease status in the Tibetan Terrier dogs was calculated as 5.5786 with degree of freedom 1, which had a pvalue of 0.80 , indicating no significant association.

\section{Conclusion}

The presented data indicate that the detected polymorphisms in the coding and adjacent intronic regions of canine CLCN3 can be excluded as disease harboring mutations in the examined dogs. Therefore it seems to be likely that the entire CLCN3 can be excluded as a candidate gene for the late-onset NCL phenotype in Tibetan Terrier and PON dogs. As the candidate gene approach did not reveal the causative gene in Tibetan Terrier and PON dogs it might be indicated to perform a genome wide linkage scan using NCL segregating families to map the canine chromosome region harboring the deleterious gene.

\section{Methods}

\section{Sequence analysis}

The human reference CLCN3 mRNA [GenBank:NM 001829] was used as query in cross-species BLAST searches against the dog genome assembly (Boxer genome assembly 1.1). A single canine genomic contig of 577,638 bp was isolated [GenBank:AAEX01020012]. The human mRNA sequence was used to identify putative

Table 2: CLCN3 genotypes in NCL-affected and control dogs

\begin{tabular}{|c|c|c|c|c|c|c|}
\hline \multirow[t]{2}{*}{ Genotype } & \multicolumn{5}{|c|}{ Tibetan Terrier } & \multirow{2}{*}{$\begin{array}{l}\text { PON } \\
1 / 2\end{array}$} \\
\hline & $\mathrm{I} / \mathrm{I}$ & $\mathrm{I} / 2$ & $3 / 4$ & $1 / 5$ & $1 / 6$ & \\
\hline NCL-affected (n) & 4 & & 1 & I & & 1 \\
\hline $\begin{array}{l}\text { NCL-non-affected } \\
\text { (n) }\end{array}$ & 5 & I & & I & I & \\
\hline
\end{tabular}

I Genotypes correspond to the deduced haplotypes shown in Table I. 
Table 3: Primer sequences for the amplification of canine CLCN3 cDNA

\begin{tabular}{lccc}
\hline Primer & Sequence $\left(5^{\prime}-3^{\prime}\right)$ & Localization within canine CLCN3 & $T_{M}\left({ }^{\circ} \mathrm{C}\right)$ \\
\hline 5' RACE outer primer & TGTACGAGCCAGGACCTTCT & exon 4/exon 5 junction & 60 \\
5' RACE inner primer & TTTGTCATTTCCCATGCTGA & exon 2 & 60 \\
3' RACE outer primer & TGCTTTAGTGGCTGCATTTG & exon 8 & 60 \\
3' RACE inner primer & TGACTGTCTCCCTGGTGGTT & exon 10 & 60 \\
CLCN3_FI & ATGGATGCTGCTTCTGATCC & exon I & 60 \\
CLCN3_RIO & CAGCAGCCAGAGTGGTATGA & exon 10 & 60 \\
\hline
\end{tabular}

exons in the canine genomic sequence used for dog specific RACE primer design. Total RNA from lung tissue of a normal female Beagle (Biocat, Heidelberg, Germany) was used for amplification of RACE PCR products. Isolation of full length cDNA for the canine CLCN3 gene was achieved by a modified rapid amplification of cDNA ends (RACE) protocol with the FirstChoiceTM RNA ligase-mediated (RLM)-RACE kit (Ambion Europe, Huntingdon, UK). Briefly, in RLM-RACE uncapped RNAs were dephosphorylated before the cap of full-length messenger RNAs (mRNAs) was removed enzymatically. After this step an RNA oligonucleotide adaptor was ligated to the 5'-end of the decapped mRNAs. As only full-length RNAs carried a 5 -phosphate group, the adaptor was expected to ligate exclusively to full-length mRNAs, while the dephosphorylated other RNAs were not able to undergo a ligation reaction. RT-PCR using two pairs of nested gene-specific (Table 3) and adaptor-specific primer pairs (Ambion) were then used to amplify the complete 5'-end of the CLCN3 CDNA according to the instructions of the manufacturer. Similarly, the 3'-end was amplified using two pairs of nested gene-specific and 3'-adaptor-specific primers. 5'- and 3'-RACE products and an additional $1885 \mathrm{bp}$ RT-PCR product using sense and antisense primers from exon 1 and 10 (Table 3 ) were cloned into pDrive plasmid vectors using the Qiagen PCR cloning kit (Qiagen, Hilden, Germany) and several clones were sequenced. The obtained canine cDNA sequences were aligned with partially overlapping canine EST sequences corresponding to the human CLCN3 [GenBank:BM537636, CF411209, BI398115, BU749098, BQ83 9554], and CLCN3 isoform e [GenBank:BM536915],

Table 4: Primer sequences for the amplification of canine CLCN3 exons

\begin{tabular}{|c|c|c|c|c|c|}
\hline Forward primer & Sequence $\left(5^{\prime}-3^{\prime}\right)$ & Reverse primer & Sequence $\left(5^{\prime}-3^{\prime}\right)$ & $\mathrm{T}_{\mathrm{M}}\left({ }^{\circ} \mathrm{C}\right)$ & Product size (bp) \\
\hline CLCN3_ExI_F & $\begin{array}{l}\text { AGCAGGGGTGGA } \\
\text { AGAAATG }\end{array}$ & CLCN3_ExI_R & $\begin{array}{c}\text { AACTACAGAACCG } \\
\text { CCCAGC }\end{array}$ & 60 & 233 \\
\hline CLCN3_Ex2_F & $\begin{array}{l}\text { ACCTAGTTCACCA } \\
\text { TTGTCTCTCA }\end{array}$ & CLCN3_Ex2_R & $\begin{array}{l}\text { TATTTTGGCTGCC } \\
\text { AGAGGTC }\end{array}$ & 60 & 312 \\
\hline CLCN3_Ex3_F & $\begin{array}{l}\text { ACCCCTTGCTCTC } \\
\text { AAATCCT }\end{array}$ & CLCN3_Ex3_R & $\begin{array}{l}\text { TTGTAGGGTGAAG } \\
\text { GAGAGAACT }\end{array}$ & 60 & 418 \\
\hline CLCN3_Ex4_F & $\begin{array}{l}\text { GTCTCAACACTCC } \\
\text { AAAAGTGGAC }\end{array}$ & CLCN3_Ex4_R & $\begin{array}{l}\text { CTGTAATTAAACG } \\
\text { GAGACTCATCTCA }\end{array}$ & 60 & 321 \\
\hline CLCN3_Ex5_F & $\begin{array}{l}\text { TGTGGAAGTAAGC } \\
\text { CAAGAAACTC }\end{array}$ & CLCN3_Ex5_R & $\begin{array}{c}\text { CTCCCCCTAAAGG } \\
\text { CAAAAAG }\end{array}$ & 60 & 318 \\
\hline CLCN3_Ex6_F & $\begin{array}{l}\text { AAGTGTTCCTGTT } \\
\text { TCCTGAATGA }\end{array}$ & CLCN3_Ex6_R & $\begin{array}{l}\text { GACTGAGCAGTAC } \\
\text { TGGGGATG }\end{array}$ & 60 & 459 \\
\hline CLCN3_Ex7_F & $\begin{array}{l}\text { TTGGAAAGAGGTA } \\
\text { GCCATCG }\end{array}$ & CLCN3_Ex7_R & $\begin{array}{l}\text { GGCTTTTCTCAAG } \\
\text { GTAAAGAACAT }\end{array}$ & 60 & 936 \\
\hline CLCN3_Ex8_F & $\begin{array}{l}\text { GCTGCAGCAAAAA } \\
\text { TTAGACCA }\end{array}$ & CLCN3_Ex8_R & $\begin{array}{l}\text { AAATGGAACCCAA } \\
\text { AAGATAAGAA }\end{array}$ & 60 & 781 \\
\hline CLCN3_Ex9_F & $\begin{array}{l}\text { AGTTTTATTTTGTAC } \\
\text { TAGGATTTTGCTC }\end{array}$ & CLCN3_Ex9_R & $\begin{array}{c}\text { CAATAGCAGTACT } \\
\text { GTTTCATTTCTGT } \\
\text { G }\end{array}$ & 60 & 474 \\
\hline CLCN3_ExI0_F & $\begin{array}{c}\text { TCCTGTCCTCCTT } \\
\text { GACCAAT }\end{array}$ & CLCN3_ExI0_R & $\begin{array}{c}\text { CCCCCAGAAACCC } \\
\text { AACTAAT }\end{array}$ & 60 & 579 \\
\hline CLCN3_ExII_F & $\begin{array}{l}\text { GGGACCAAATTCA } \\
\text { TGGGATA }\end{array}$ & CLCN3_ExII_R & $\begin{array}{l}\text { TGTTTTGGCAAAG } \\
\text { ATGTGGT }\end{array}$ & 60 & 511 \\
\hline CLCN3_ExI2_F & $\begin{array}{l}\text { GGACCTGGGATTT } \\
\text { CGAACC }\end{array}$ & CLCN3_Ex|2_R & $\begin{array}{l}\text { TTATTCAGCAGGC } \\
\text { ATCTGGG }\end{array}$ & 60 & 343 \\
\hline CLCN3_ExI3_F & $\begin{array}{c}\text { ATCAAAGGATGGT } \\
\text { TGCTGGA }\end{array}$ & CLCN3_ExI3_R & $\begin{array}{c}\text { TTGCGATGTCGGA } \\
\text { GTAACAG }\end{array}$ & 60 & 647 \\
\hline
\end{tabular}


respectively. The exact canine genomic structure was determined using the mRNA-to-genomic alignment program Spidey [14].

\section{Mutation analysis}

Genomic DNA was isolated from a single NCL-affected PON dog, six unrelated NCL-affected Tibetan Terrier dogs, and eight unrelated clinical unsuspicious Tibetan Terrier dogs ( $>8$ years old). Clinical neurologic, behavioral, and ophthalmologic evaluations were performed on each dog by a single external consultant veterinarian $[4,15]$. The phenotypes of the affected animals have been confirmed by detection of autofluorescent cytoplasmic inclusions within neurons throughout the retina and brain after necropsy. The 13 CLCN3 exons with flanking sequences were PCR amplified and directly sequenced with the DYEnamic ET Terminator kit (Amersham Biosciences, Freiburg, Germany) and a MegaBACE 1000 capillary sequencer (Amersham Biosciences), using PCR primers listed in table 4 as sequencing primers. The association analysis for this paper was generated using SAS/HAPLOTYPE software, Version 2.1.39 of the SAS System for Windows (2003 SAS Institute Inc., Cary, NC, USA).

\section{Authors' contributions}

AW did the mutation screen and drafted parts of the manuscript. OD proposed the idea and was responsible for funding. CD performed the RACE experiments, analyzed the sequence data, and performed manuscript editing.

\section{Acknowledgements}

We thank Dr. med. vet. R. Brahm, Dortmund, Germany, for clinical examination and Dr. med. vet. K. Matiasek, Institute of Veterinary Pathology LMU Munich, Germany, for neuropathology.

\section{References}

I. Jolly RD, Walkley SU: Lysosomal storage diseases of animals: an essay in comparative pathology. Vet Pathol 1997, 34:527-548.

2. Goebel HH, Wisniewski KE: Current state of clinical and morphological features in human NCL. Brain Pathol 2004, I 4:6I-69.

3. Riis RC, Cummings JF, Loew ER, de Lahunta A: Tibetan terrier model of canine ceroid lipofuscinosis. Am J Med Genet 1992, 42:615-62I.

4. Wrigstad A, Nilsson SE, Dubielzig R, Narfstrom K: Neuronal ceroid lipofuscinosis in the Polish Owczarek Nizinny (PON) dog. A retinal study. Doc Ophthalmol 1995, 91:33-47.

5. Mole $\mathrm{S}$ : The genetic spectrum of human neuronal ceroid-lipofuscinoses. Brain Pathol 2004, 14:70-76.

6. Katz ML, Khan S, Awano T, Shahid SA, Siakotos AN, Johnson GS: A mutation in the CLN8 gene in English Setter dogs with neuronal ceroid-lipofuscinosis. Biochem Biophys Res Commun 2005, 327:54I-547.

7. Drögemüller C, Wöhlke A, Distl O: Evaluation of the canine TPPI gene as a candidate for neuronal ceroid lipofuscinosis in Tibetan Terrier and Polish Owczarek Nizinny dogs. Anim Genet 2005, 36: I78-179.

8. Drögemüller C, Wöhlke A, Distl O: Characterization of candidate genes for neuronal ceroid lipofuscinosis in dog. J Hered 2005, 96:735-738.

9. Shibuya H, Liu PC, Katz ML, Siakotos AN, Nonneman DJ, Johnson GS: Coding sequence and exon/intron organization of the canine CLN3 (Batten disease) gene and its exclusion as the locus for ceroid-lipofuscinosis in English setter dogs. J Neurosci Res 1998, 52:268-275.

10. Melville SA, Wilson CL, Chiang CS, Studdert VP, Lingaas F, Wilton AN: A mutation in canine CLN5 causes neuronal ceroid lipofuscinosis in Border collie dogs. Genomics 2005, 86:287-294.

II. Awano T, Katz ML, O'Brien DP, Taylor JF, Evans J, Khan S, Sohar I, Lobel P, Johnson GS: A mutation in the cathepsin $D$ gene (CTSD) in American Bulldogs with neuronal ceroid lipofuscinosis. Mol Genet Metab in press. 2005 Dec 28

12. Drögemüller C, Wöhlke A, Distl O: The canine CTSD gene as a candidate for late-onset neuronal ceroid lipofuscinosis. Anim Genet 2005, 36:530-532.

13. Yoshikawa M, Uchida S, Ezaki J, Rai T, Hayama A, Kobayashi K, Kida Y, Noda M, Koike M, Uchiyama Y, Marumo F, Kominami E, Sasaki S: CLC-3 deficiency leads to phenotypes similar to human neuronal ceroid lipofuscinosis. Genes Cells 2002, 7:597-605.

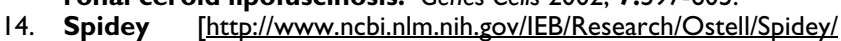
index.html]

15. Katz ML, Narfström K, Johnson GS, O'Brien DP: Assessment of retinal function and characterization of lysosomal storage body accumulation in the retinas and brains of Tibetan Terriers with ceroid-lipofuscinosis. Am J Vet Res 2005, 66:67-76.
Publish with Biomed Central and every scientist can read your work free of charge

"BioMed Central will be the most significant development for disseminating the results of biomedical research in our lifetime. " Sir Paul Nurse, Cancer Research UK

Your research papers will be:

- available free of charge to the entire biomedical community

- peer reviewed and published immediately upon acceptance

- cited in PubMed and archived on PubMed Central

- yours - you keep the copyright 